\title{
Formulation and evaluation of solid dispersions of Rofecoxib for improvement of dissolution profile
}

\author{
Vyas Jigar $^{1 \star}$, Vyas Puja ${ }^{1}$ and Patel Jayvadan ${ }^{2}$ \\ ${ }^{1}$ Sigma Institute of Pharmacy, Baroda, Gujarat, India. \\ ${ }^{2}$ Nootan Pharmacy College, Visnagar, Gujarat, India.
}

Accepted 4 April, 2011

\begin{abstract}
Rofecoxib is a non-steroidal anti-inflammatory drug, mainly used for osteoarthritis, rheumatoid arthritis, and dysmenorrhea. The major problem with this drug is its very low solubility in biological fluids, which results in poor bioavailability after oral administration. Therefore, solid dispersions of Rofecoxib with urea, polyethylene glycol (PEG) 6000 and polyvinyl pyrrolidone (PVP) K30 were prepared by different methods and evaluated with a view to increase its water solubility and hence to improve the dissolution profile. Solid dispersions were prepared and evaluated for solubility, melting point and \% practical yield. Two solid dispersions showing maximum solubility were selected and formulated into tablet. The tablets were exposed to routine quality control tests like hardness, friability, weight variation and disintegration. The dissolution profiles of these formulations were studied in $0.1 \mathrm{~N} \mathrm{HCl}$ and compared with marketed tablet as well as pure drug. At the end of $\mathbf{3 0} \mathrm{min}$, formulation TFG3 gave the highest drug release that is $99.10 \%$, followed by TSG3 $(90.32 \%)$ whereas marketed tablet and plain drug gave 71.22 and $24.14 \%$ respectively. The present study conclusively demonstrated that, solubility and dissolution profile of Rofecoxib was significantly improved by preparing solid dispersion with water soluble carriers.
\end{abstract}

Key words: Rofecoxib, solubility, solid dispersion, hydrophilic carriers, dissolution.

\section{INTRODUCTION}

Rofecoxib is a nonsteroidal anti-inflammatory drug (NSAID) prescribed for the long-term treatment of musculoskeletal complaints (Noble et al., 1996). The major drawback with this drug is poor bioavailability after oral administration. Oral bioavailability of drugs depends on its solubility and/or dissolution rate, therefore the major problem associated with these drugs, is its very low solubility in biological fluids, which results into poor bioavailability after oral administration. Among numerous ways of enhancing drug dissolution, solid dispersion (SD) of drug in a hydrophilic polymer is one of the promising techniques (Chiou et.al., 1971; Craig, 2002). Several water soluble carriers such as mannitol, urea, lactose, citric acid, polyvinyl pyrrolidone (PVP) and polyethylene glycols (PEGs) are used as carriers for solid dispersions

\footnotetext{
${ }^{*}$ Corresponding author. E-mail: jigs4u_80@yahoo.co.in, drjrvyas@yahoo.co.in. Tel: +91-9428764734.
}

(Chiou et.al., 1971; Swarbrick, 2002; Leunner et al., 2000).

The main objective of the present study was to investigate the possibility of improving the water solubility and dissolution profile of Rofecoxib by preparing solid dispersions with various water-soluble polymers such as polyethylene glycol 6000 , polyvinyl pyrrolidone $\mathrm{K} 30$ and urea exploring various methods of preparation of solid dispersions. These carriers have shown very strong potential of improving dissolution of several drugs (Craig, 1990; Van den Mooter et al., 1998). The prepared solid dispersions were extensively evaluated for solubility, melting point and percentage practical yield. Three solid dispersions showing promising performance were selected and formulated into tablet using carbopol 940, microcrystalline cellulose, starch, lactose, talc, and Mg. stearate. The prepared tablets were exposed to routine quality control tests like hardness, percentage friability, weight variation, disintegration to qualify the tablets for further study. Dissolution study of tablets containing 
Table 1. Formulation of solid dispersions of Rofecoxib.

\begin{tabular}{|c|c|c|c|}
\hline Carrier & Form. code & D:C ratio & Method \\
\hline \multirow{3}{*}{$\begin{array}{l}\text { PEG } \\
6000\end{array}$} & SG1 & $1: 3$ & \multirow{6}{*}{$\begin{array}{l}\text { Solvent } \\
\text { evaporation }\end{array}$} \\
\hline & SG2 & $1: 6$ & \\
\hline & SG3 & $1: 9$ & \\
\hline \multirow{3}{*}{$\begin{array}{l}\text { PVP } \\
\text { K30 }\end{array}$} & SV2 & $1: 3$ & \\
\hline & SV2 & $1: 6$ & \\
\hline & SV3 & $1: 9$ & \\
\hline \multirow{3}{*}{ Urea } & SU1 & $1: 3$ & \\
\hline & SU2 & $1: 6$ & \\
\hline & SU3 & $1: 9$ & \\
\hline \multirow{3}{*}{$\begin{array}{l}\text { PEG } \\
6000\end{array}$} & FG1 & $1: 3$ & \multirow{8}{*}{ Fusion } \\
\hline & FG2 & $1: 6$ & \\
\hline & FG3 & $1: 9$ & \\
\hline PVP & - & - & \\
\hline K30 & - & - & \\
\hline \multirow{3}{*}{ Urea } & FU1 & $1: 3$ & \\
\hline & FU2 & $1: 6$ & \\
\hline & FU3 & $1: 9$ & \\
\hline \multirow{3}{*}{$\begin{array}{l}\text { PEG } \\
6000\end{array}$} & CG1 & $1: 3$ & \multirow{9}{*}{$\begin{array}{l}\text { Co-grinding } \\
\text { mixture }\end{array}$} \\
\hline & CG2 & $1: 6$ & \\
\hline & CG3 & $1: 9$ & \\
\hline \multirow{3}{*}{$\begin{array}{l}\text { PVP } \\
\text { K30 }\end{array}$} & CV1 & $1: 3$ & \\
\hline & CV2 & $1: 6$ & \\
\hline & CV3 & $1: 9$ & \\
\hline \multirow{3}{*}{ Urea } & CU1 & $1: 3$ & \\
\hline & CU2 & $1: 6$ & \\
\hline & CU3 & $1: 9$ & \\
\hline
\end{tabular}

Form. code=Formulation code; $\mathrm{D}: \mathrm{C}$ ratio $=$ Drug: Carrier ratio.

solid dispersions, marketed tablet and plain drug powder was performed and compared by ANOVA. All the three tablets formulations were also evaluated for stability study.

\section{MATERIALS AND METHODS}

Rofecoxib was obtained as a gift sample from Ranbaxy Laboratories Pvt Ltd (New Delhi, India). Rofebax $12.5 \mathrm{mg}$ conventional tablets (Ranbaxy Laboratories Pvt Ltd, New Delhi) were purchased from the market. Urea, polyethylene glycol 6000 and polyvinyl pyrrolidone $\mathrm{K} 30$ of pharmacopoeial grade were purchased from SD Fine Chemicals Ltd, Mumbai. All reagents were of A.R. grade. All materials were used as obtained without any modification or purification. Distilled water was used for all the experiments.

\section{Preparation of solid dispersions}

Solid dispersions were prepared with three carriers that is $\mathrm{PEG}$ 6000 , PVP K30 and urea by three different methods; that is by solvent evaporation, fusion and co-grinding; as shown in Table 1.

\section{Solvent evaporation}

Solid dispersions were prepared by dissolving required amount of drug and carriers in weight ratio of 1:3, 1:6 and 1:9 into methanol:acetone 1:1 solvent system. The solvent was evaporated at $60^{\circ} \mathrm{C}$ on water bath with continuous stirring to obtain dry mass. The dry mass was pulverized by passing through sieve no. 44 followed by sieve no. 60. The dried mass was stored in dessicator until further use.

\section{Fusion method}

Solid dispersions were prepared by melting the carriers in porcelain dish (at around 55 to $60^{\circ} \mathrm{C}$ in case of PEG 6000 and 130 to $135^{\circ} \mathrm{C}$ in case of urea) on water bath, dispersing the drug onto the molten carrier and cooling immediately on ice bath with continuous stirring to dry mass. The dry mass was pulverized by passing through sieve no. 44 followed by sieve no. 60. The dried mass was stored in dessicator until further use.

\section{Cogrinding}

The cogrinding mixtures of Rofecoxib were prepared using PEG 6000, PVP K30 and urea in 1:3, 1:6 and 1:9 weight ratios in a mortar and pestle. The dry mass was pulverized by passing through sieve no. 44 followed by sieve no. 60 . The dried mass was stored in dessicator until further use.

\section{Evaluation of solid dispersions}

\section{Solubility}

The saturation solubility of drug as well as all the solid dispersions was determined by dispersing $1 \mathrm{~g}$ of drug or solid dispersion onto $100 \mathrm{ml}$ of phosphate buffer saline $(\mathrm{pH} 7.4)$ contained in glass bottle and shaken for not less than $12 \mathrm{~h}$. Solubility was then determined in $\mathrm{mg} / \mathrm{ml}$ using spectrophotometry with $\lambda_{\max } 285 \mathrm{~nm}$ after necessary dilutions and recorded in Table 2 .

\section{Melting point}

Melting point of drug, polymer and all the solid dispersions was determined thrice, using precision melting point apparatus and recorded in Table 2.

\section{Practical yield}

Maximum quantity of solid dispersions were collected and weighed accurately. The percentage practical yield was calculated in percentage (\%) w/w using the following equation: 
Table 2. Evaluation of solid dispersion of Rofecoxib.

\begin{tabular}{|c|c|c|c|}
\hline Form. code & $\mathrm{s}$ & M.P (으) & PPY \\
\hline SG1 & 0.231 & 115.9 & 98.11 \\
\hline SG2 & 0.423 & 97.3 & 96.30 \\
\hline SG3 & 0.943 & 93.1 & 97.18 \\
\hline SV1 & 0.215 & 127.6 & 98.11 \\
\hline SV2 & 0.384 & 118.9 & 98.53 \\
\hline SV3 & 0.551 & 109.3 & 97.89 \\
\hline SU1 & 0.019 & 116.0 & 94.56 \\
\hline SU2 & 0.040 & 108.1 & 95.22 \\
\hline SU3 & 0.058 & 102.5 & 95.51 \\
\hline Drug & 0.010 & 207 & - \\
\hline Urea & $\mathrm{s}$ & 131 & - \\
\hline FG1 & 0.112 & 104.6 & 97.11 \\
\hline FG2 & 0.567 & 96.3 & 96.74 \\
\hline FG3 & 1.103 & 89.2 & 95.58 \\
\hline FV1 & - & - & - \\
\hline FV2 & - & - & - \\
\hline FV3 & - & - & - \\
\hline FU1 & 0.011 & 112.4 & 97.13 \\
\hline FU2 & 0.024 & 105.7 & 95.28 \\
\hline FU3 & 0.046 & 99.4 & 96.66 \\
\hline PEG & s & 57 & - \\
\hline CG1 & 0.027 & 139.2 & 94.59 \\
\hline CG2 & 0.039 & 110.5 & 95.02 \\
\hline CG3 & 0.074 & 98.7 & 94.38 \\
\hline CV1 & 0.014 & 171.6 & 99.10 \\
\hline CV2 & 0.021 & 156.3 & 97.23 \\
\hline CV3 & 0.032 & 145.3 & 97.71 \\
\hline CU1 & 0.013 & 162.7 & 96.27 \\
\hline CU2 & 0.025 & 146.4 & 98.50 \\
\hline CU3 & 0.038 & 130.8 & 96.81 \\
\hline PVP & $\mathrm{s}$ & 162 & - \\
\hline
\end{tabular}

$\mathrm{n}=3$; Percentage of SD (Standard deviation) was found to be less than $4 \%$ for all the observations. S=Saturation solubility $(\mathrm{mg} / \mathrm{ml})$; $\mathrm{M} . \mathrm{P}=$ Melting point; $\mathrm{PPY}=\mathrm{Percentage}$ practical yield; $\mathrm{s}=$ soluble - all the carriers were found to be soluble in the proportions they were used in preparation of solid dispersion.

$\%$ practical yield $=($ Weight of SD/Total weight of all the ingredients taken initial) $\times 100$

\section{Preparation of tablets containing solid dispersion}

Tablets containing solid dispersions equivalent to $12.5 \mathrm{~g}$ of Rofecoxib were prepared by direct compression method after mixing with required amount of different ingredients as shown in in Table 3.

\section{Evaluation of tablet}

Tablets containing solid dispersion as well as marketed tablet were exposed to routine quality control tests like hardness, friability, weight variation and disintegration, as recorded in Table 4, to qualify for further testing of dissolution study. The dissolution study was performed on 8 vessel USP type II dissolution test apparatus in $0.1 \mathrm{~N} \mathrm{HCl}$ with constant temperature and speed at $37 \pm 2{ }^{\circ} \mathrm{C}$ and 50 rpm respectively. Aliquots were withdrawn at different time intervals, analyzed by UV-visible spectrophotometric method and cumulative percentage release of drug was recorded in Table 5 and presented as chart in Figure 1. The tablets were also evaluated for stability by accelerated stability testing method. Tablets were stored at $45^{\circ} \mathrm{C}$ with $65 \% \mathrm{RH}$ in incubator for about 8 weeks and the data was recorded in Table 6.

\section{RESULTS AND DISCUSSION}

Solid dispersions of Rofecoxib were prepared successfully by solvent evaporation, fusion and co-grinding method with carriers; that is PEG 6000, PVP K30 and urea except PVP K30 in fusion method due the high melting point of PVP K30. The solubility of drug was found to be $0.01 \mathrm{mg} / \mathrm{ml}$ and agrees well with literature (Seedher and Bhatia, 2003), which was increased significantly in all the solid dispersions. Table 2 shows highest solubility was obtained with FG3 $(1.103 \mathrm{mg} / \mathrm{ml})$ followed by SG3 $(0.943 \mathrm{mg} / \mathrm{ml}), \mathrm{FG} 2(0.567 \mathrm{mg} / \mathrm{ml})$, SV3 $(0.551$ $\mathrm{mg} / \mathrm{ml})$, SG2, $(0.423 \mathrm{mg} / \mathrm{ml})$, etc. It is also reflecting from Table 2 that, there is significant reduction in melting point of solid dispersion as compared to pure drug which might be due to the conversion of crystalline form to amorphous form. The increasing order of meting point of some of solid dispersions as per Table 2 is FG3, SG3, FG2, SG2, FU3, etc. The drug is in crystalline form, PVP K30 and PEG 6000 are semi crystalline materials Mashru et al., 2005; Evangelos et al., 2007; Vasilios et al., 2007; Ilse et al., 2005, Guy et al., 1998. PEG 6000 melts at relatively lower temperature, as compared to drug and hence it brought down the overall melting point of prepared solid dispersion and also, the conversion of crystalline form to amorphous is higher in fusion method, as compared to other methods because of high energy input.

Hence, the batch FG3 (solid dispersion by fusion method using PEG 6000) showed the highest solubility enhancement. The second highest solubility enhancement was seen with batch SG3 (solid dispersion by solvent evaporation method using PEG 6000) with the same reasons. In addition, the hydrophilicity of PEG 6000 is higher and the melting point is lower, as compared to other two carriers, which makes PEG 6000 a potential carrier for solubility enhancement experiments. This observation also supports the work done by Maria et al. (1994) and Verheyen et al. (2002) who obtained very good results of solubility enhancement using PEG 6000 . The data of Batch FG2 and SV3 showed that, both the batches have nearly the same potential of solubility enhancement of the crystalline drug and this observation draws a positive conclusion, in favor of fusion method among the methods used and PEG 6000 among the carriers used.

The percentage practical yield was determined to 
Table 3. Formulation of tablet containing solid dispersions.

\begin{tabular}{lcc}
\hline \multirow{2}{*}{ Tablet ingredients } & \multicolumn{2}{c}{ Formulations of tablet } \\
\cline { 2 - 3 } & TSG3 & TFG3 \\
\hline Solid dispersion equivalent to 12.5 mg of Rofecoxib & 125 & 125 \\
Carbopol 974 & 6.45 & 6.45 \\
Lactose & 25.49 & 25.49 \\
Starch & 12.90 & 12.90 \\
Micro crystalline cellulose & 75.0 & 75.0 \\
Talc & 2.58 & 2.58 \\
Mg. stearate & 2.58 & 2.58 \\
Total tablet weight & 250 & 250 \\
\hline
\end{tabular}

TSV3, TFG3, TPU3=Tablets of batch SV3, FG3 and PU3. All the weights shown are in mg.

Table 4. Evaluation of tablets.

\begin{tabular}{ccccc}
\hline \multirow{2}{*}{ Formulation } & \multicolumn{4}{c}{ Evaluation parameters of tablets } \\
\cline { 2 - 5 } & Hardness $\mathbf{( k g / \mathbf { c m } ^ { \mathbf { 2 } } )}$ & Friability (\%) & Weight variation & Disintegration time (s) \\
\hline TSG3 & 4.5 & 0.62 & $250 \pm 7.3$ & 35 \\
TFG3 & 4.8 & 0.51 & $250 \pm 8.1$ & 41 \\
MP & 5.1 & 0.33 & $105 \pm 2.5$ & 112 \\
\hline
\end{tabular}

$\mathrm{n}=3$; Percentage of SD (\% Standard deviation) was found to be less than $5 \%$ for all the observations.

Table 5. Dissolution study of tablet containing solid dispersions and marketed tablet.

\begin{tabular}{cccccc}
\hline \multirow{2}{*}{ Time $(\boldsymbol{m i n})$} & \multicolumn{5}{c}{ Cumulative percentage release of drug } \\
\cline { 2 - 6 } & TSV3 & TFG3 & TPU3 & MP & Plain drug \\
\hline 5 & 35.29 & 41.26 & 28.38 & 20.18 & 6.84 \\
10 & 61.98 & 72.87 & 51.76 & 37.55 & 11.87 \\
15 & 74.60 & 85.25 & 61.88 & 51.89 & 16.31 \\
30 & 90.32 & 99.10 & 78.13 & 71.22 & 24.14 \\
45 & 96.56 & 99.80 & 88.45 & 84.15 & 29.57 \\
60 & 97.88 & 99.89 & 96.91 & 91.23 & 33.71 \\
\hline
\end{tabular}

$\mathrm{n}=3 ; \mathrm{MP}=$ Market preparation; \%SD was found to be less than $4.5 \%$ for all the readings.

understand the recoverability of the formulation. All formulations have shown more than $94 \%$ practical yield, as per Table 2, reflecting feasibility of the methods. After the preliminary study, two solid dispersions that is FG3 and SG3, were selected and formulated into tablet as shown into Table 3 . Here, the authors have put a bias towards fusion method as solvent residue is a major demerit of solvent evaporation and poor conversion ratio of crystalline to amorphous form. The tablets prepared with solid dispersions were compared with conventional marketed tablet and plain drug by dissolution test. Both the tablet containing solid dispersions and marketed tablets were exposed to quality control testing, like hardness, friability, weight variation and disintegration test. Table 4 suggests that all tablet formulations passed in quality control tests. The results of dissolution study, as in Table 5 reveals that, dissolution profile of Rofecoxib is improved significantly by incorporating into solid dispersion. At the end of $30 \mathrm{~min}$, tablet TFG3 released the highest amount of drug that is $99.10 \%$ followed by TSG3 $(90.32 \%)$ which is significantly (ANOVA, $p=0.01$ ) higher than marketed tablet formulation $(71.22 \%)$. This data suggests that formulating the drug into solid dispersion using hydrophilic carrier enhances water solubility due to conversion of crystalline powder into amorphous form, which is reflected as decrease in melting point of solid dispersions as compared to pure drug. ANOVA test analysis of stability study data indicates that, all the 

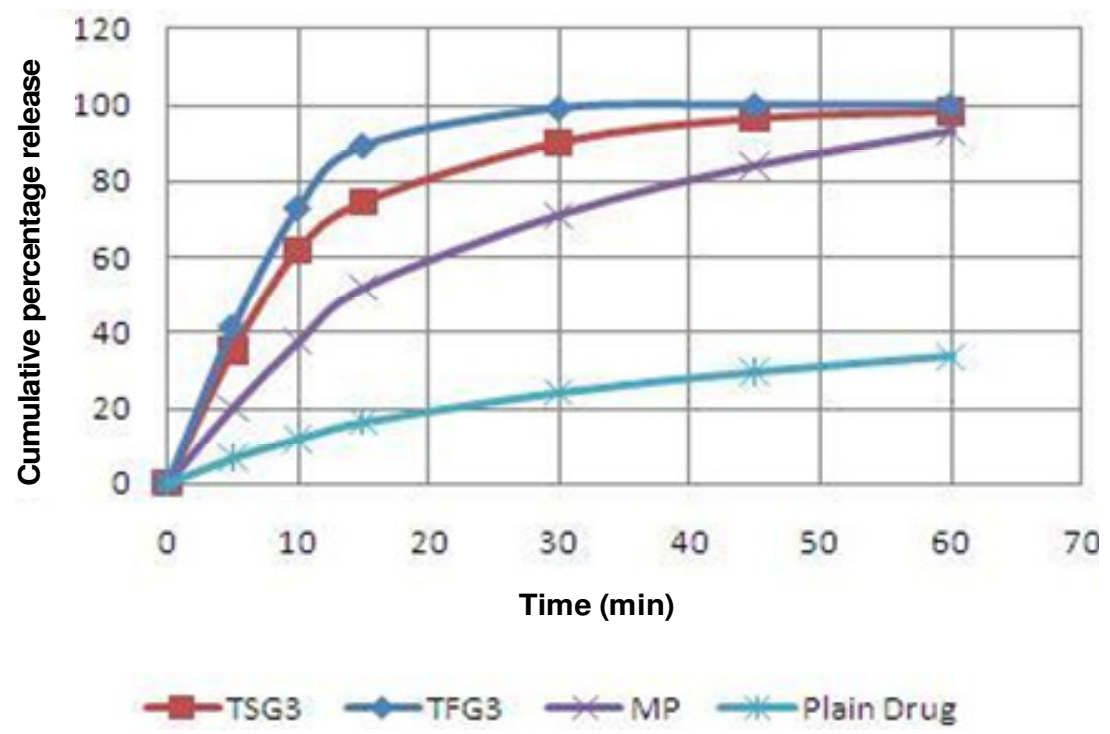

Figure 1. Cumulative percentage release of drug from different formulations in dissolution study.

Table 6. Stability study of tablets and plain drug.

\begin{tabular}{ccccc}
\hline \multirow{2}{*}{$\begin{array}{c}\text { Time } \\
\text { (weeks) }\end{array}$} & \multicolumn{4}{c}{ CPR of drug at the end of 30 min } \\
\cline { 2 - 5 } & TSG3 & TFG3 & MP & Plain drug \\
\hline 1 & 90.29 & 99.10 & 71.18 & 24.15 \\
3 & 89.98 & 99.08 & 71.55 & 24.14 \\
5 & 89.60 & 99.15 & 71.89 & 24.11 \\
7 & 90.12 & 98.57 & 71.22 & 24.13 \\
9 & 89.56 & 99.11 & 70.85 & 23.97 \\
12 & 89.88 & 98.49 & 70.77 & 23.92 \\
\hline
\end{tabular}

$\mathrm{n}=3$; Percentage of SD was found to be less than $3.3 \%$ for all the observations, CPR=Cumulative percentage release; MP=Market preparation.

formulations were found stable without any significant difference.

\section{Conclusion}

The solubility and dissolution profile of Rofecoxib - a poorly water soluble drug, was significantly improved by preparing solid dispersion with water soluble carrier like PEG 6000, PVP K30 and urea by solvent evaporation, fusion and co-grinding techniques. Solid dispersion prepared by fusion method using PEG 6000 at $1: 9$ drug:carrier ratio has shown highest improvement in the dissolution profile of Rofecoxib. The carrier used are of GRAS grade and the techniques explored are relatively easy, simple, quick, inexpensive, and reproducible suggesting that solid dispersion is a trustworthy alternative for solubility enhancement of poorly water soluble drug.

\section{REFERENCES}

Chiou WL, Riegelman S (1971). Pharmaceutical applications of solid dispersion system. J. Pharm. Sci., 60: 1281-1302.

Craig DQM (1990). Polyethylene glycol and drug release. Drug Dev. Ind. Pharm., 16: 2514-2515.

Craig DQM (2002). The mechanisms of drug release from solid dispersions in water-soluble polymers. Int. J. Pharm., 231: 131-144.

Evangelos K, Emmanuel G, Michael PS, Konstantinos A, Dimitrios B (2007). Investigation of the release mechanism of a sparingly watersoluble drug from solid dispersions in hydrophilic carriers based on physical state of drug, particle size distribution and drug-polymer interactions Eur. J. Pharm. Biopharm., 66: 334-347.

Guy VM, Augustijns P, Blaton N, Kinget R (1998). Physicochemical characterization of solid dispersions of temazepam with polyethylene glycol 6000 and PVP K30. Int. J. Pharm., 164: 67-80.

Ilse W, Dieter K, Geert V, Annelies D, Koen H, Jef P, Marcus B, Guy VM (2005). Study of the physicochemical properties and stability of solid dispersions of loperamide and PEG6000 prepared by spray drying. Eur. J. Pharm. Biopharm., 59: 119-126.

Leunner C, Dressman J (2000). Improving drug solubility for oraldelivery using solid dispersions. Eur. J. Pharm. Biopharm., 50: 47-60.

Maria VM, Ines CR, Antonio C (1994). Physical characteristics and dissolution kinetics of solid dispersions of ketoprofen and polyethylene glycol 6000. Int. J. Pharm., 108: 101-107.

Mashru RC, Sutariya VB, Sankalia MG, Yagnakumar P (2005). Characterization of solid dispersions of rofecoxib using differential scanning calorimeter, J. Therm. Anal. Calorim., 82(1): 167-170.

Noble S, Baifour JA (1971). Rofecoxib - A Drug Profile. Drugs, 51:424430.

Seedher N. and Bhatia S (2003). Solubility Enhancement of Cox-2 Inhibitors Using Various Solvent Systems. AAPS Pharm. Sci. Tech., 4(3): 1-9.

Swarbrick B (2002). Encyclopedia of Pharmaceutical Technology. Marcel Dekker Inc, $2^{\text {nd }}$ Ed, 1: 641-647.

Vasilios IT, Michael PS (2007). Theoretical study of hydrogen bond interactions of felodipine with polyvinylpyrrolidone and polyethyleneglycol. J. Mol. Struct. (THEOCHEM), 803: 29-38.

Verheyen S, Blaton N, Kinget R, Guy VM (2002). Mechanism of increased dissolution of diazepam and temazepam from polyethylene glycol 6000 solid dispersions. Int. J. Pharm., 249: 45-58. 